\title{
The Role of Saline Enema in Reduction of Intussusception Under Ultra Sonographic Guide a Study of 40 Patients in Alkarama Teaching Hospital
}

\author{
Dr.Ahmed kadhum mohammed FJMC( RAD) \\ followship of jordanian medical council (radiology)AL-karama teaching hospital \\ Dr.Haider Ibraheem Khaleel \\ Pediatric surgery Central Child Teaching Hospital of Baghdad \\ Dr. Hussein Ali Abed Ahmad
}

Teacher in Wassit medical collage M. B. Ch. B- F.I.C.M.S- AL-karama teaching hospital Iraq-wasit province

\begin{abstract}
Background:

enema reduction of the intussusception under US guide is widely used as a useful alternative to surgical management. This procedure is simple with no radiational effect, less complication rate with good outcome and the parents can stay with their child during the whole procedure.
\end{abstract}

Aim of study :

We tried to present our experience in HRIUSG by the use of normal saline enema and to evaluate its safety, outcome and to identify the risk variables for enema failure.

Methodology :

From the 1st of June 2016 to 1 st of January 2017, we received about 45 children at children welfare hospital (medical city complex) that confirmed sonographically to have intussusception. Five patients were excluded from the study because of contraindications (peritonitis, perforation and shock). 40 children were developed enema reduction under sonographic guide.

Results :

From 40 children underwent HRIUSG their age presentation range from 3 months to 32 month, $67.4 \%$ had respiratory infection while $32.6 \%$ had gastroenteritis. We had a successful rate about $79 \%$ with a median of 1 trial and only 3 patients $(9.3 \%)$ developed recurrence within 1 st $24 \mathrm{hr}$. from the 9 patients underwent surgery we had 8 patients had manual reduction and one patient underwent resection of the bowel. Only 3 patients had PLP. 1 patient ( $2.3 \%$ ) was reported to have complication ( perforation over sewn ).

Age, gender, duration of symptoms not significantly affect the outcome $\mathrm{P}$ value $<0.05$ while bleeding with stool, initial mass in the left colon and rectum, presence of free fluid and more trial numbers were a bad prognostic factors for enema failure .

Conclusion:

1. HRIUSG is simple, safe, less costly, practical, less messy ,no radiational exposure with a low complication rate 2. Age, gender, Duration of symptoms did not affect the outcome significantly.

3. Although bleeding with stool, left colon intussusception mass and free peritoneal fluid is a risk factor for failure of HRIUSG but they are not absolute contraindication.

4. The better scenario for enema reduction success is a patient presented with symptoms $<24 \mathrm{hr}$. with no bleeding stool and a mass in the cecum and ascending colon with no free peritoneal fluid.

Keywords: saline enema; reduction; intussusception ; ultrasound guide .

DOI: $10.7176 / \mathrm{JHMN} / 73-04$

Publication date: April $30^{\text {th }} 2020$

\section{INTRODUCTION}

Intussusception is the most frequent cause of bowel obstruction in infants and toddlers. It is an acquired invagination of the proximal bowel (intussusceptum) into the distal bowel (intussuscipiens). It was first described in 1674 by Paul Barbette of Amsterdam, defined by Treves in 1899, and operated on successfully in 1873 by John Hutchinson.1,2

Although intussusception was accurately described by John Hunter in 1793, Hippocrates (born circa 490 BC) recommended that treatment of "ileus" consist of connecting a bellows to the anus and inflating the bowel with air if hydrostatic reduction, possibly with the use of oil, failed. The first successful operative reduction was performed by Jonathan

Hutchinson in 1871. Hirschsprung first described hydrostatic reduction of intussusception in 1876 and in 1905 described 107 patients successfully treated with this method. In the 1920s Scandinavian radiologists reported 
the use of fluoroscopically controlled barium enema for reduction of intussusception. Ravitch's standardization of techniques with barium helped nonoperative reduction gain more widespread acceptance. In 1959 the use of air reduction was first reported, and, more recently, thousands of patients in China have been treated successfully this way3, The word intussusception is derived from the Latin words intus (within) and suscipere (to receive). Intussusception is the invagination of one part of the intestine into another (Fig. 1). Three cylinders of intestinal wall are involved. The inner and middle cylinders are the invaginated bowel (intussusceptum), and the outer cylinder is the recipient of the invaginated bowel (intussuscipiens). 4

The lamina propria of the small intestine is a loose areolar network extending between intestinal glands and into the core of the villi, and containing scattered lymphocytes and isolated lymphatic nodules. These nodules are more numerous in the distal small intestine and may be sufficiently large as to occupy the whole mucosa. Visible masses of lymphoid tissue may occur along the anti-mesenteric border of the ileum,up to $2 \mathrm{~cm}$ in length,and are known as Peyer's patches.Lymphoid hyperplasia within the intestine may result in enlarged Peyer's patches, which serve as the lead point for intussusception in 'idiopathic' cases. 5

Each intussusception has the following pathologic anatomy: as the intussusception develops with its prograde bowel peristalsis, the proximal invaginated bowel (intussusceptum) carries its mesentery into the distal recipient bowel (intussuscipiens). The mesenteric vessels are angulated, squeezed, and compressed between the layers of the intussusceptum. This causes intense local edema of the intussusceptum, which inturn produces venous compression, congestion, and stasis leading to an outpouring of mucus and blood from the engorged intussusceptum, the classic red currant jelly stool. If this process continues unabated, bowel congestion and pressure increase and ultimately produce ischemic changes leading to bowel necrosis in the intussusceptum. In most cases, ischemic necrosis needs more than 72 hours to develop.

If the ischemic process goes undiagnosed, bowel obstruction, perforation, or sepsis leads to death within 5 days. In rare cases, the intussusceptum can become gangrenous, and slough and the bowel may fuse.No free perforation occurs, and the separated necrotic intussusceptum may pass out of the rectum. 4

\section{Material and methods :}

A prospective study of 40 patients underwent HRIUSG was done in Alkarama teaching hospital in medical city complex from 1st June 2018 to 1st January 2019.

All patients were received from either outpatient clinic or emergency unit as a suspicion of intussusception, the following workup done for each patient:

1: A full history was taking regarding age, gender, duration of symptoms (screaming attack, vomiting, bleeding with stool etc....) and preceding symptoms like gastroenteritis or respiratory symptoms.

2. Full general and abdominal examination done for the patients seeking for signs of intussusception (presence of abdominal mass, site of the mass, per rectal examination for detecting bleeding with stool or palpable mass).

3. All patients sent for basic laboratory tests including CBP, RFT and serum electrolyte, blood group.

4. All patients were sent for erect abdominal X- ray.

5. All patients underwent abdominal sonography using ...sonographic criteria including (presence of an intussusception mass, site and size of the mass, presence of free fluid in the abdomen).

After confirmation of the diagnosis we explain to the parents their child condition and the sequences and the future plan for management regarding non-operative procedure and the risk of failure and probability of conversion to operative management.

We admitted the patients to the surgical ward for correction of dehydration and electrolyte disturbances and we took an informed consent from the parents about the procedure and risk of repeated attempts, perforation, failure and the need for surgery. Five of patients excluded from our study and they were in need for urgent laparotomy because of sings of peritonitis, perforation, hemodynamically unstable and suspicion of the presence of PLP (pathological leading point), patients younger than 3 months and older than 3 years were excluded.

While preparing for hydrostatic reduction, 10 of the patients ( $25 \%$ ) were received sedation diazepam 0.1 $\mathrm{mg} \backslash \mathrm{kg}$ rectally while surgical team were ready for surgery .

The patient were taken to the sonographic examination room, saline enema were done using Foleys catheter [ $20-22 \mathrm{~F}$ ] introduced in the rectum without lubricant up to $10 \mathrm{~cm}$ and the child putted in the left

lateral position while one of the parents close to himlher, the balloon was inflated up to $25 \mathrm{ml}$ of distilled water with confirmation of its position close to the mass under ultrasonography using 5-10 MHZ (Toshiba-japan ) device and buttock plaster used .

A warm normal saline enema were used at a height of $100-120 \mathrm{~cm}(120 \mathrm{mmhg})$ above the child's table up to $1000 \mathrm{ml}$ for up to $30 \mathrm{~min}$. while the sonarist observing the flow of the enema and the reduction of the mass and detecting any sign of perforation ( free fluid ). ilium.

Sings of complete reduction are complete reduction of the mass and reflux of the enema into the terminal

After complete the procedure the enema filled the bowel were evacuated and the sonarist (before deflating 
the balloon of the Foley's catheter) were confirming the reduction of the mass and assuring no perforation nor free fluid in the abdominal cavity found and searching for PLP and checking bowel peristalsis condition.

The patient then taken to the ward and kept nothing orally and under observation for $24 \mathrm{hr}$. then a formal abdominal ultrasound was done for confira tion of reduction and exclude recurrence after $24 \mathrm{hr}$.

Anderson darling test was done to asses if continuous variables follow normal distribution, if follow normal distribution than mean and standard deviation used, if did not follow normal distribution than median and interquartile range ( $25 \%$ to $75 \%$ percentile range) will be used to present the data (boxplot and whisker used to present them graphically).

Discrete variables presented using there number and percentage used to present the data, chi square test used to analyze the discrete variable or Fisher exact test used to analyze the distribution between 2 groups (used instead of chi square for $2 \times 2$ table, if total sample $<20$ and if 2 or more with expected frequency less than 5).

Mann Whitney U test used to analyzed the differences in median of two groups (if they do not follow normal distribution)

Binary logistic regression analysis used to calculate the odd ratio (OR) and their $95 \%$ confidence intervals, when the outcome can be categorized into 2 binary levels, and if appropriate probability plot used to present the relationship SPSS 20.0.0 software package used to make the statistical analysis, $\mathrm{p}$ value considered when appropriate to be significant if less than 0.05

1- outcome of HRIUSG .

In this study, we received 40 patients which presented as intussusception. All of them underwent HRIUSG, 32 patients had successful reduction done with up to 3 trials and 8 patients failed with a whole success rate $79 \%$.

From the resolved group we had $9.3 \%$ ( 3 of 32 ) developed recurrence in the first $24 \mathrm{hr}$. all of them had HRIUSG, 2 patients reduced and 1 patient failed and need surgery.

All of the 9 patients which failed to reduced underwent urgent surgical intervention , 8 patients were manually reduced while only 1 needed resection of the unhealthy bowel there were 3 PLP $(7.5 \%)$ lymphoma, polyp and Meckel's diverticulum, all of them underwent resection.

One patient developed perforation (2.3\%) during the procedure and sewing of the perforation was done

2: Statistical presentation regarding to gender.

Of the 40 patients included in our study there was 25 male ( $62.5 \%)$ and 15 female ( $37.5 \%)$.

3 - Statistical presentation regarding age, gender and its relationship to outcome.

From 34 success trials, 13 was female $(38.2 \%)$ and 21 was male $(61.8 \%)$.

From 9 failed trials we had 2 female ( $22.2 \%)$ and we had 7 males (77.8\%) as shown in table 2 and figure 7 .

We noticed that both age and gender did not affect the outcome

4- duration of symptoms ( DOS ) and type of infection and its relation to outcome.

From 43 trials we had $21(48.8 \%)$ with DOS $<24 \mathrm{hr}$. with success rate $(90.4 \%$ [19 of 21$])$ and we had $22(51.2 \%)$ with DOS $>24 \mathrm{hr}$ with success rate ( $68.1 \%$ [15 of 22$)$.

Duration of symptoms did not differ significantly between patients with successful and failed outcome $p$ value (0.132).

The type of infection also did not affect the outcome significantly, .

5- symptoms of the patients and their relation to the outcome .

Bleeding with stool is higher in patients with failed outcome (77.8\% [ 7 of 9 ] vs $41.2 \%$ [ 14 of 34]) however this higher proportion did not reach statistical significance; both vomiting and screaming attacks did not differ significantly between both groups.

6- mass characteristics and ultrasound finding related to outcome .

From 43 patients, 9 ( $20.9 \%$ ) had no papable mass with success rate $(26.5 \%)$. from 43 patients we had $34(79.1 \%)$ had a palpable mass with success rate $73.5 \%$ ). from statistical point of view there is no relation between mass presence and outcome P value 0.83

Regarding the site of the mass , 30 patients ( $69.85 \%$ ) had a mass in the cecum and ascending colon with a success rate $76.5 \%$.

Masses at the transverse colon level account for only 10 patients $(23.3 \%)$ with success rate $23.5 \%$.

Masses reached the left colon and rectum account for only 3 patients $(7 \%)$ with high failure rate reaching $100 \%$.

Regarding free fluid in the abdomen 10 patients ( $23.3 \%$ ) had + ve free fluid associated with high failure rate $88.9 \%$. free fluid also significantly associated with failed outcome $\mathrm{P}$ value $<0.001$.

7- enema procedure characteristics and its relation to outcome.

Increase number of trials associated significantly with failed outcome, while trial time was lower in failed outcome (median $15 \mathrm{~min}$ versus $20 \mathrm{~min}$ ) it did not reach statistical significance, amount of enema did not associated with outcome.

8- The no. of the trials and its relation to outcome.

Table 7 illustrate that as the number of attempts increase there is increase in the failure rate in which in the patients 
with first attempt there was $4 \%$ failure rate, in the 2 nd attempt there was $11.1 \%$ failure rate in the 3 rd attempt the failure rate increase to $77.8 \%$.

\section{9- the use of sedative agents and the outcome.}

The use of sedation did not associate significantly with outcome, however $8 / 10$ of the patients who had been used sedation had successful outcome .

10- logistic regression analysis and risk factors :

free fluid was the strongest predictor of failure in outcome (128 folds), followed by increased trial number (10.7 folds), than bloody stool (5.0 folds), than longer than 24 hours duration of symptoms (4.4 folds), and transverse and descending colon location (4.1 folds) all these associated with failed outcome. Only free fluid presence was independent predictor of failed outcome;

\section{Discussion}

Ultrasonography can be used usefully as a diagnostic method for the intussusception with high sensitivity and specifity.52

HRIUSG (hydrostatic reduction of intussusception under sonographic guide) is regarded promising, helpful non-operative method since its first described by Kim et al 53 because it is very simple, less costly, effective, consuming less time with no radiation rate and less complication. The procedure associated with less morbidity and less probability of fluctuation in the intraluminal colonic pressure as in air enema, also less risk of peritonitis even with perforation like barium enema. There is no mortality rate was reported as in the air enema.54,55,56

The success rates that were published ranging from (75\% to $95 \%$ which seems to be similar to the results using air enema. 57,58,59,60

In this thesis the success rate was $79 \%$ which seems to be not that different from other results that were published.

Some studies like Kim et al.53and Bai et al.59 they used a chlorpromazine medication before the enema reduction with success rate reaching 96\%.while other studies like Rohrschneider's and Tröger's used (chloral hydrate or valium ) with a success rate $90 \% .67$

In our study we had been used diazepam rectally in only 10 ( 43 ) cases $23.2 \%$ with success rate in 8 ( 10 ) $80 \%$.we thought that not using sedation in all of our patients may be contributing factor to our low success rate, and we plan for developing a suitable, practical strategy for sedating children before the procedure of HRIUSG.

In our department the procedure were done by residents under training period, so it may be a factor for lower success rate and we plan to do a more formal protocol to decrease this variation. Crystal et al.63 and Bai et al.59found that there is correlation between the outcome and the experience of the radiologist and procedure operators.

Rohrschneider and Tröger 67 found that the longer the procedure, the more probability of reduction (the success rate can be increased up to $90 \%$ when more time spending for more than 45 minutes.in our study from statistical point of view we found in 34 success trial the median reduction time is 20 min with a range from( 15 min. - $30 \mathrm{~min})$. and a median enema amount of $650 \mathrm{ml}$ with a range from $(300 \mathrm{ml}-1000 \mathrm{ml})$.

In this study from statistical point of view we found that age, gender, vomiting, screaming attacks, preceding symptoms like gastroenteritis, respiratory infection shows no significant association $\mathrm{P}$ value $>0.05$. as shown in table $2,3,4$. He et al.68discussed the risk factors for failed

HRIUSG, they found that age,gender,DOS were not affect the outcome significantly while mass localization ( left colon and rectum ), free fluid in the abdomen, bleeding with stool were a risk variables for failure.36

A DOS which prolonged more than $24 \mathrm{hr}$. in our study decrease the success rate but statistically not significant $\mathrm{P}$ value (0.132).Katz et al.69found that DOS more than $12 \mathrm{hr}$. is a risk factor for reduction failure, while Fike et al.70 found that any patient with DOS more than $24 \mathrm{hr}$. is a significant factor for unsuccessful enema reduction. we expect the reasons may be incapability of the patients to determine the exact time of symptoms or the parents error to clarify the time of symptoms precisely.

there is one study 71 of pneumatic reduction found there is no correlation between DOS and reducibility. in our study the patients that were presented with bleeding stool was $48.80 \%$ ( 21 of 43 ) with lower success rate ( $66.6 \%$ [ 14 of 21 ] ) and our multivariate analysis show it is a poor prognostic factor OR 5.0 and this is goes with He et al 68. There is one study reported bleeding with stool as a risk factor for failure.70

In this study we had only $7 \%$ ( 3 of 34 ) from the patients presented with distally located mass with high failure rate $100 \%$ ( 3 of 3 ) and $\mathrm{P}$ value $<0.02$, and in the multivariate analysis an intussusception reaches the left colon and rectum regarded as a bad prognostic factor with OR value of 4.062. There is some of the researches like Crystal et al.,Fike and Khanna et als 63,70,72 regarded that the initial mass location distally (left colon or rectum) is a poor prognostic factor.

The presence of free fluid in the abdomen was the main strongly poor prognostic factor in our research. The patients that presents with + ve free fluid in abdominal US account for $23.3 \%$ ( 10 of 43 ) with very high failure rate $80 \%$ (8 of 10) with OR 128 in the multivariate analysis.our results are seeming similar to the results of Britton 
and Wilkinson 73 which found that a success rate is better (up to $93 \%$ ) with the absence of free fluid in the abdomen and they regard the presence of trapped fluid within the mass is a poor prognostic factor which decreasing the success rate down to $25 \%$. Some researches like Mirilas et al and Feinstein et al. regarded the presence of small amount of free fluid did not affect the reducibility.74,75

In this study we had a recurrence rate $9.3 \%$ ( 3 of 32 ) .and our result is seems to be in the usual accepted range $10-15 \%$. Which is goes with Niramis et al.44

in our study we had only one patient developed perforation $2.3 \%$ ( 1 of 43 ) which is similar to Tareen et al.71 so the enema reduction under US guide is so safe when we respect the inclusion criteria.

We used only three trials as a maximum no. in our study and we found increasing the failure rate with more trial numbers although we had 9 patients underwent 3 trials with a success rate $22.2 \%$ ( 2 of 9 ).

Rohrschneider and Tröger 67were suggest trying the last trial on the operating theater under GA before surgery which could be a successful maneuver for increasing outcome. we plan to have a such facility in our management protocol to increase our success rate and improve outcome.

The limited experience of our center residents of the sonographic department overcame the using of more variables in our study like the thickness of the bowel wall74, trapped fluid within the intussusceptum mass 76 , presence of lymph nodes within the mass 77 and the Doppler finding of the mass to assess vascularity and viability of the involved bowel as in Lim et al.78

\section{Conclusion and recommendations :}

Conclusion :

1. HRIUSG is simple, safe, less costly, practical, no radiational exposure with a low complication rate

2. Age, gender, DOS did not affect the outcome significantly.

3. Although bleeding with stool, left colon intussusception mass and free peritoneal fluid is a risk factor for failure of HRIUSG but they are not absolute contraindication.

4. The better scenario for successful enema reduction is a patient presented with symptoms $<24 \mathrm{hr}$. with no bleeding stool and a mass in the cecum and ascending colon with no free peritoneal fluid.

\section{Recommendations:}

1. success rate can be increased using systemic sedation.

2. the procedure done by well-trained pediatric surgery team.

3. US done by well-trained radiologist using more variables.

39

\section{References}

1. Barbette P. Oeuvres Chirurgiques et Anatomiques. Geneva: Francois Miege; 1674

2. Hutchinson J. A successful case of abdominal section for intussusception. Proc R Med Chir Soc 1873;7:195-8.

3. John W. DiFiore, MD. intussusception. 1999

4. Paul M. Columbani, Stefan Scholz. Intussuseption, Arnold G. Coran, MD,N. Scott Adzick, MD,Thomas (. pediatric surgery, 7th ed. Hodder Headline Group: ; 2012. pp. 1093-1108.

5. David M. Burge,D. Mervyn Griffiths,Henrik A. Steinbrecher,Robert A. Wheeler,Robert A. Wheeler. pediatric surgery. 338 Euston Road, London NW1 3BH: Hodder Headline Group; 2005.p 199

6. Bines JE, Liem NT, Justice FA, et al. Risk factors for intussusception in infants in Vietnam and Australia: Adenovirus implicated, but not rotavirus. J Pediatr 2006;149:452-60.

7. Belongia EA, Irving SA, Shui IM, et al. Real-time surveillance to assess risk of intussusception and other adverse events after pentavalent, bovine-derived rotavirus vaccine. Pediatr Infect Dis J 2010;29:1-5.

8. Shui IM, Baggs J, Patel M, et al. Risk of intussusception following administration of a pentavalent rotavirus vaccine in ultrasound infants. JAMA 2012;307:598-604.

9. Alexandra C. Maki, Mary E. Fallat. intussusception. George W. Holcomb III, MD MBA ,J. Patrick Murphy, MD ,Daniel J. Ostlie, MD ,Shawn D. St. Peter, MD et al. (eds). ashcraft's pediatric surgery, $6^{\text {th }}$ ed. china: ; 2014. pp. 531-538.

10. . Weihmiller SN, Buonomo C, Bachur R. Risk stratification of children being evaluated for intussusception. Pediatrics 2011;127: e296-303.

11. Burke LF, Clark E. Ileocolic intussusception-a case report. J Clin Ultrasound 1977;5:346-7

12. Henrikson S, Blane CE, Koujok K, et al. The effect of screening sonography on the positive rate of enemas for intussusception. Pediatr Radiol 2003;33:190-3.40

13. Navarro O, Daneman A. Intussusception. Part 3: Diagnosis and management of those with an identifiable or predisposing cause and those that reduce spontaneously. Pediatr Radiol 2004;34:305-12.

14. Gu L, Zhu H, Wang S, et al. Sonographic guidance of air enema for intussusception reduction in children. Pediatr Radiol 2000; 30:339-42. 
15. Fecteau A, Flageole H, Nguyen LT, et al. Recurrent intussusception: Safe use of hydrostatic enema. J Pediatr Surg 1996;31: 859-61.

16. M M Ahmad, M D Wani, H M Dar, I N Mir, H A Wani, A N Raja. SAJS. An experience of ultrasound-guided hydrostatic reduction of intussusception at a tertiary care centre 2016; 54(no.1): .

17. Hirschsprung H. Et Tilfaelde af suakat Tarminvagination. Hospitals-Tidende 1876;3:321-7

18. Ravitch MM. Intussusception in Infants and Children. Springfield, IL; 1959.

19. Applegate KE. Clinically suspected intussusception in children: Evidence-based review and self-assessment module. AJR Am J Roentgenol 2005;185(Suppl. 3):S175-83.

20. Daneman A, Navarro O. Intussusception. Part 1: A review of diagnostic approaches. Pediatr Radiol 2003;33:79-85.

21. Navarro OM, Daneman A, Chae A. Intussusception: the use of delayed, repeated reduction attempts and the management of intussusceptions due to pathologic lead points in pediatric patients.AJR Am J Roentgenol 2004;182:1169-76.

22. ShaStRi Mona Digant, Seth Rucha, DeSai eKta. Ultrasound Guided Reduction of an Ileocolic Intussusception by a Hydrostatic Method by Using Normal Saline Enema in Paediatric Patients: A Study of 30 Cases. Journal of Clinical and Diagnostic Research. 2012 december; Vol-6(10).

23. Holt LE. The Diseases of Infancy and Childhood: For the Use of Students and Practioners of Medicine. New York: Appleton; 1897.

24. Guo JZ, Ma XY, Zhou QH. Results of air pressure enema reduction of intussusception: 6,396 cases in 13 years. J Pediatr Surg 1986;21:1201-3.

25. Dobranowski J. Manual of procedures in gastrointestinal radiology, Springer-Verlag, New York 1990.

26. Stringer, DA, Babyn, P. Pediatric gastrointestinal imaging and intervention, 2nd ed, BC Decker, Philadelphia 2000.41

27. Seiji Kitagawa, MD; Mohamad Miqdady, MD . Intussusception in children . up to date online 2008; 16

28. Daneman A, Navarro O. Intussusception. Part 1: A review of diagnostic approaches. Pediatr Radiol 2003;33:79-85.

29. Kao C, Tseng SH, Chen Y. Laparoscopic reduction of intussusception in children by a single surgeon in comparison with open surgery. Minim Invasive Ther Allied Technol 2011;20:141-5.

30. Reijnen, JA, Festen, C, van Roosmalen, RP. Intussusception: factors related to treatment. Arch Dis Child 1990; 65:871.

31. Maoate, K, Beasley, SW. Perforation during gas reduction of intussusception. Pediatr Surg Int 1998; 14:168.

32. Sohoni, A, Wang, NE, Dannenberg, B. Tension pneumoperitoneum after intussusception pneumoreduction. Pediatr Emerg Care 2007; 23:563.

33. Armstrong, EA, Dunbar, JS, Graviss, ER, et al. Intussusception complicated by distal perforation of the colon. Radiology 1980; 136:77.

34. Humphry, A, Ein, SH, Mok, PM. Perforation of the intussuscepted colon. AJR Am J Roentgenol 1981; 137:1135

35. Sohoni A, Wang NE, Dannenberg B. Tension pneumoperitoneum after intussusception pneumoreduction. Pediatr Emerg Care 2007;23:563-4.

36. Waldhausen JH. Intussusception. In: Mattei P, editor. Fundamentals of Pediatric Surgery. New York: Springer; 2011

37. Koh CC, Sheu JC, Wang NL, et al. Recurrent ileocolic intussusception after different surgical procedures in children. Pediatr Surg Int 2006;22:725-8.

38. van der Laan M, Bax NM, van der Zee DC, et al. The role of laparoscopy in the management of childhood intussusception. Surg Endosc 2001;15:373-6.

39. Bailey KA, Wales PW, Gerstle JT. Laparoscopic versus open reduction of intussusception in children: A single-institution comparative experience. J Pediatr Surg 2007;42:845-8.

40. Kia KF, Mony VK, Drongowski RA, et al. Laparoscopic vs open surgical approach for intussusception requiring operative intervention. J Pediatr Surg 2005;40:281-4.42

41. Burjonrappa SC. Laparoscopic reduction of intussusception: An evolving therapeutic option. JSLS 2007;11:235-7.

42. Bonnard A, Demarche M, Dimitriu C, et al. Indications for laparoscopy in the management of intussusception: A multicenter retrospective study conducted by the French Study Group for Pediatric Laparoscopy (GECI). J Pediatr Surg 2008;43:1249- 53.

43. Hill SJ, Langness SM, Wulkan ML. Laparoscopic versus Open Reduction of Intussusception in Children: Experience Over a Decade. Poster presented at Southeastern Surgical Congress Feb 2012 Birmingham, AL, 2012

44. Niramis R, Watanatittan S, Kruatrachue A, et al. Management of recurrent intussusception: Nonoperative or operative reduction? J Pediatr Surg 2010;45:2175-80. 
45. Mirza B. Recurrent intussusception: Management options. APSP J Case Rep 2011;2:9.

46. Champoux AN, Del Beccaro MA, Nazar-Stewart V. Recurrent intussusception. Risks and features. Arch Pediatr Adolesc Med 1994;148:474-8.

47. Navarro O, Dugougeat F, Kornecki A, et al. The impact of imaging in the management of intussusception owing to pathologic lead points in children. A review of 43 cases. Pediatr Radiol 2000;30: 594-603.

48. Holcomb GW III, Ross AJ III, O’Neill JA Jr. Post-operative intussusception: Increasing frequency or increasing awareness? South Med J 1991;84:1334-9.

49. Bai YZ, Chen H, Wang WL. A special type of postoperative intussusception: Ileoileal intussusception after surgical reduction of ileocolic intussusception in infants and children. J Pediatr Surg 2009;44:755-8.

50. Linke F, Eble F, Berger S. Postoperative intussusception in childhood. Pediatr Surg Int 1998;14:175-7.

51. Laje P, Stanley CA, Adzick NS. Intussusception after pancreatic surgery in children: A case series. J Pediatr Surg 2010;45:1496-9.

52. Del Pozo G, Albillos JC. Intussesception in children-current concept in diagnosis and enema reduction. Radiographics. 1999;19:299-319.43

53. Kim Y, Choi B, Yeon K, Kim C. Diagnosis and treatment of childhood intussusception using real-time ultrasonography and saline enema: preliminary report. J Korean Soc Med Ultrasound1982; 1:66-70.

54. Krishnakumar, Hameed S, Maheshwari U. Ultrasound Guided Hydrostatic Reduction in the Management of Intussusception. Indian Journal of Paediatrics. 2006; 73(3): 217-20

55. Khong PL, Peh WC, Lam CH, Chan KL. Ultrasound-guided hydrostatic reduction of childhood intussusception: technique and demonstration. Radiographics. 2000; 20: 1818.

56. Alan Daneman, Oscar Navarro. Intussusception, Part 2: An update on the evolution of management. Pediatric Radiology. 34 ( 2): 97-108.

57.Wang, Liu. Enema reduction of intussusception by hydrostatic pressure under ultrasound guidance: a report of 377 cases. J Pediatr Surg 1988;23:814-8.

58. Peh WC, Khong PL, Chan KL, et al. Sonographically guided hydrostatic reduction of childhood intussusception using Hartmann's solution. AJR Am J Roentgenol 1996;167:1237-41.

59. Bai YZ, Qu RB,Wang GD, et al. Ultrasound-guided hydrostatic reduction of intussusceptions by saline enema: a review of 5218 cases in 17 years. Am J Surg 2006;192:273-5.

60. Rohrschneider WK, Tröger J. Hydrostatic reduction of intussusception under USguidance. Pediatr Radiol 1995;25:530-4.

61. Shehata S, El Kholi N, Sultan A, et al. Hydrostatic reduction of intussusception: barium,air or saline? Pediatr Surg Int 2000;16:380-2.

62. Di Renzo D, Colangelo M, Lauriti G, et al. Ultrasound-guided Hartmann's solution.enema: first-choice procedure for reducing idiopathic intussusception. Radiol Med2012;117:679-89.44

63. Crystal P, Hertzanu Y, Farber B, et al. Sonographically guided hydrostatic reduction of intussusception in children. J Clin Ultrasound 2002;30:343-8.

64. Digant SM, Rucha S, Eke D. Ultrasound-Guided reduction of an ileocolic intussusception by a Hydrostaticmethod by using normal saline enema in paedriatric patients: a study of 30 cases. J Clin Diagn Res 2012;6:1722-5.

65. Chan KL, Saing H, Peh WC, et al. Childhood intussusception: ultrasound-guided Hartmann's solution hydrostatic reduction or barium enema reduction? J Pediatr Surg 1997;32:3-6.

66. Choi SO, ParkWH,Woo SK. Ultrasound-guided water enema: an alternative method of nonoperative treatment for childhood intussusception. J Pediatr Surg 1994;29:498-500.

67.Rohrschneider WK, Tröger J. Hydrostatic reduction of intussusception under US guidance. Pediatr Radiol $1995 ; 25: 530-4$

68. He N, Zhang S, Ye X, et al. Risk factors associated with failed sonographically guided saline hydrostatic intussusception reduction in children. JUM 2014;33:1669-75.

69. Katz M, Phelan E, Carlin JB, Beasley SW. Gas enema for the reduction of intussusception: relationship between clinical signs and symptoms and outcome. AJR Am J Roentgenol 1993; 160:363-366.

70. Fike FB, Mortellaro VE, Holcomb GR III, St Peter SD. Predictors of failed enema reduction in childhood intussusception. J Pediatr Surg 2012;47:925-927.

71. Tareen F, Ryan S, Avanzini S, Pena V, McLaughlin D, Puri P. Does the length of the history influence the outcome of pneumatic reduction of intussusception in children? Pediatr Surg Int 2011; 27:587-589.

72. Khanna G, Applegate K. Ultrasound-guided intussusception reduction: are we there yet? Abdom Imaging 2008; $33: 38-40$

73. Britton I, Wilkinson AG. Ultrasound features of intussusception predicting outcome of air enema. Pediatr Radiol 1999; 29:705-710.

74. Mirilas P, Koumanidou C, Vakaki M, Skandalakis P, Antypas S, Kakavakis K. Sonographic features indicative of hydrostatic reducibility of intestinal intussusception in infancy and early childhood. Eur Radiol 
2001;11:2576-2580.

75. Feinstein KA, Myers M, Fernbach SK, Bhisitkul DM. Peritoneal fluid in children with intussusception: its sonographic detection and relationship to successful reduction. Abdom Imaging 1993; 18:277-279.

76. Nianan He, PhD, Shenglong Zhang, MD, Xianjun Ye, MD, Xiaoqian Zhu, MD, Zhihong Zhao, MD, Xiufang Sui, MD. Risk factors associated with failed sonographically guided saline hydrostatic intussusception reduction in children. $2014 ; 33: 1669-1675$.

77. Koumanidou C, Vakaki M, Pitsoulakis G, Kakavakis K, Mirilas P. Sonographic detection of lymph nodes in the intussusception of infants and young children: clinical evaluation and hydrostatic reduction. $A J R A m$ JRoentgenol 2002; 178:445-450.

78. Lim HK, Bae SH, Lee KH, Seo GS, Yoon GS. Assessment of reducibility of ileocolic intussusception in children: usefulness of color Doppler sonography. Radiology 1994; 191:781-785. 